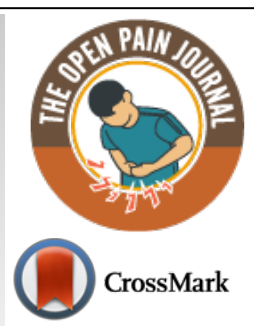

RESEARCH ARTICLE

\title{
Sacroiliac Joint Pain: A Study of Predisposing Factors in an Indonesian Hospital
}

\author{
Yusak M.T. Siahaan ${ }^{*}$ and Vinson Hartoyo \\ Department of Neurology, Siloam Hospital Lippo Villagen, Jalan Boulevard Jendral Sudirman, Tangerang 15811, Indonesia
}

\begin{abstract}
:
Background:

Sacroiliac joint pain has been one of the most common causes of lower back pain, regardless of gender. Diminished pain after an anaesthetic block has been the only gold standard diagnostic procedure, making the diagnosis become challenging due to the needs of fluoroscopic procedure. Thus, a study to find predisposing factors of sacroiliac joint pain is pivotal for primary prevention and prognosis predictor.

Objective:

Our study aims to find predisposing factors of sacroiliac joint pain in Indonesian patients.

Methods:

We conducted a prospective study on patients with a chief complaint of lower back pain whose pain diminished after anaesthetic block.

Results:

We found 99 subjects, with a male to female ratio of 1:2.19, aged from 21 to 75 years old (mean: 42.88 ). In addition to multiparous pregnancy and obesity, office-based occupation and prolonged sitting duration are also becoming major predisposing factors of sacroiliac joint pain (50.5\% and $51.51 \%$ respectively). We also found majority of the patients with a history of vertical trauma with the onset of pain 1 year post trauma.

\section{Conclusion:}

We found some factors that can be considered to trigger sacroiliac joint pain that are: female gender, advancing age, pregnancy history, long sitting duration and office worker occupation.
\end{abstract}

Keywords: Indonesia, Low back pain, Predisposing factors, Sacroiliac joint pain, Multiparous pregnancy, Vertical trauma.

\begin{tabular}{l|l|l|l} 
Article History & Received: May 12, 2018 & Revised: November 27, 2018 & Accepted: January 11, 2019
\end{tabular}

\section{INTRODUCTION}

Sacroiliac joint pain is defined as pain originating from unusual movement in the sacroiliac joint structure. The pain provoked by sacroiliac joint dysfunction can cause a range of disabilities, including a continuously intense pain level accompanied by a limited range of motion. Sacroiliac joint pain has become one of the biggest contributors to lower back pain of mechanical origin, regardless of gender. It has been estimated that $13 \%$ of prolonged lower back pain cases are caused by sacroiliac joint pain, which has a prevalence of $15-38 \%$. Women have a 3-4 times higher risk of suffering from sacroiliac joint pain than men [1 - 3].

* Address correspondence to this author at Department of Neurology, Siloam Hospital Lippo Villagen, Jalan Boulevard Jendral Sudirman, Tangerang 15811, Indonesia; Tel: +6221 081586270028 ;

E-mail: yusak.mangara@siloamhospitals.com
Diagnosing the pain caused by inflammation of the sacroiliac joint can be challenging due to its ambiguous clinical mani-festations, which are difficult to distinguish from herniated intervertebral discs, facet joint pain, and gluteal muscle spasms. Radiological examinations, which usually help exclude other musculoskeletal disorders, have been proven to have low specificity and sensitivity in diagnosing sacroiliac joint pain, and they will, most likely, show no abnormalities [1, 4 - 6]. Anesthetic blocks have long been considered the gold standard procedure for diagnosing sacroiliac joint pain, with the pain being alleviated after the injection. One disadvantage of this procedure is the requirement for supporting facilities, which can only be met in tertiary healthcare centers [7].

Numerous studies have been conducted to gain more information about sacroiliac joint pain, including researching the factors that trigger this pain, which will contribute to 
improved diagnostic procedures. However, most of these studies have been conducted in the Western region, while the data about the predisposing factors for sacroiliac joint pain in the Eastern region is still lacking [4, 8, 9]. Therefore, we conducted a study to determine the clinical profile of patients with sacroiliac joint pain and its predisposing factors in Indonesia.

\section{MATERIALS AND METHODS}

This research study included 99 patients with age ranging from 17-75 years old who presented to the outpatient Neurology Clinic of Siloam Hospital Lippo Village in Tangerang, Indonesia, with chief complaints of pain in the buttock region, with or without radiation. Their physical examination findings included positive Fortin finger test results and positive results in 1 or 2 of the provocative tests. All patients included in this study were evaluated with regard to their predisposing factors, pain scores, and neurological examinations. Then, the diagnosis of sacroiliac joint pain was made by using an anesthetic block and observing a decrease in the pain score of more than $75 \%$. The patients with autoimmune disease histories and disorders seen in their pelvic radiological scans were excluded from this study.

The injection procedure used in this study was based on the procedure from a study by Liliang et al. First, the patient was placed in a prone position on a fluoroscopy table in order to visualize the median line of the sacroiliac joint. Then, the fluoroscopy machine was placed in an ipsilateral oblique position and slowly moved $10-20^{\circ}$ towards the contralateral oblique position until optimal visualization of the hyperlucent region of the sacroiliac joint was obtained. The injection target was then located in the inferior medial part of the sacroiliac joint corresponding to the posterior side. Finally, a $2 \%$ lidocaine solution was injected medially, $1-2 \mathrm{~cm}$ above the inferior side of the sacroiliac joint [10]. The pain score evaluation was conducted 15 minutes after the injection, and the results were deemed positive if there was a decrease of a minimum of $75 \%$ in the pain score.

\section{RESULTS}

A total of 99 subjects ( 31 males and 68 females, with a male to female ratio of 1:2.19) aged 21 to 75 years old (mean $=42.88$ years old) were included in this study (Table 1 ). The majority of the subjects were $40-49$ years old $(35.35 \%$, $\mathrm{n}=35$ ). Interestingly, the majority of the female subjects had pregnancy histories $(79.41 \%, n=54)$, with sacroiliac joint pain being found more often in those subjects with histories of more than 3 pregnancies $(30.9 \%, n=32)$ when compared to those with histories of 3 or less pregnancies $(22.3 \%, n=22)$. When comparing the body mass indexes, we found that the majority of the subjects fell into the $25-29.9 \mathrm{~kg} / \mathrm{m}^{2}$ range, which is categorized as overweight $(28.3 \%)$. With regard to the occupational history, we found that the majority of the subjects $(50.5 \%)$ worked in offices in which they spent most of their time sitting ( 8 hours or more). We also found that $54.5 \%$ of the subjects reported histories of lower back trauma (vertical fall) with post-trauma intervals of greater than 1 year $(35.3 \%)$. Sacroiliac joint pain was also detected in those subjects who reported that they participated in routine exercise more than 4 times a week for a duration of more than 1 hour $(10.1 \%, \mathrm{n}=10)$. More than half of the subjects $(51.51 \%, \mathrm{n}=51)$ also reported prolonged sitting durations of more than 6 hours as one of the predisposing factors.

\section{DISCUSSION}

Sacroiliac joint pain is one of the most common causes of lower back pain encountered in daily practice. Numerous treatment modalities have been developed for lower back pain, including sacroiliac joint pain. Initially, a patient is usually prescribed conservative treatment, such as bed rest, anti-inflammatory medications, and physical therapy [2]. Inter-ventional procedures (e.g., intra-articular injections) are reserved for those who fail to respond to conservative treat-ment. This type of treatment is usually administered using a freehand technique, such as unguided, palpation-guided, blind, or clinical examination-guided injections. However, some studies have indicated that these approaches are unreliable. One of the earliest studies conducted by Jones et al. reported a heterogeneous needle placement success rate [11]. A more recent study by Rosenberg et al. revealed that in 33 patients undergoing freehand sacroiliac joint injections, there were intraarticular needle placements in only $22 \%$ of the injections [12]. Fortunately, ultrasound-guided sacroiliac joint injections have demonstrated high success rates of up to $90 \%$, resulting in better clinical responses, which is one of the reasons why we chose the technique that we used in our study $[13,14]$.

Many studies have been conducted to determine the predisposing factors for sacroiliac joint pain. Some of the most important predisposing factors reported were the gender, age, body mass index, trauma history, and activity rate.

\subsection{Gender and Age}

Women have long been considered to have a greater risk of developing lower back pain than men. The lower back pain rate increases significantly during pregnancy, and it continues to increase after delivery. The differing anatomy of the female pelvic region, when compared to males, has been speculated to play a part in the distinctive functions of both pelvic regions. Overall, the sacrum to sacroiliac joint ratio is different between the genders, with significant changes observed in males with an advancing age $[2,8,15]$.

Irwin et al. determined that the gender and age were not correlated with the pathological causes of sacroiliac joint pain, but they did find that sacroiliac joint pain occurred more commonly in females than males (61\% and 39\%, respec-tively) [8]. The results of that study were similar to those of a study by Taheri et al., which reported that sacroiliac joint pain was found more commonly in female patients $(57.9 \%)$. That study also found an increased frequency in the $40-55$ years old age group in both genders [16]. These results support those from a study by DePalma et al., which reported that sacroiliac joint pain was associated with older age [17]. This increased frequency may be attributed to the diminishing flexibility of the ligaments with age [15]. 
Table 1. Demographic information and risk factors of the subjects.

\begin{tabular}{|c|c|c|c|}
\hline No & Parameter & $\mathbf{N}$ & $\%$ \\
\hline \multirow[t]{3}{*}{1} & Gender & & \\
\hline & Male & 31 & 31.3 \\
\hline & Female & 68 & 68.7 \\
\hline \multirow[t]{6}{*}{2} & Age & & \\
\hline & $20-29$ & 11 & 11.11 \\
\hline & $30-39$ & 24 & 24.24 \\
\hline & $40-49$ & 35 & 35.35 \\
\hline & $50-59$ & 23 & 23.23 \\
\hline & $>60$ & 6 & 6.07 \\
\hline \multirow[t]{3}{*}{3} & Pregnancy & & \\
\hline & No & 14 & 20.6 \\
\hline & Yes & 54 & 79.4 \\
\hline \multirow[t]{3}{*}{4} & History of Pregnancy & & \\
\hline & Less than 3 times & 22 & 40.7 \\
\hline & More than 3 times & 32 & 59.3 \\
\hline \multirow[t]{6}{*}{5} & Body Mass Index & & \\
\hline & Underweight & 5 & 5.1 \\
\hline & Normal & 50 & 50.5 \\
\hline & Overweight & 28 & 28.3 \\
\hline & Obese Class 1 & 14 & 14.1 \\
\hline & Obese Class 2 & 2 & 2.0 \\
\hline \multirow[t]{5}{*}{6} & Occupation History & & \\
\hline & Unemployed & 7 & 7.1 \\
\hline & Housewife & 23 & 23.2 \\
\hline & Office worker & 50 & 50.5 \\
\hline & Field worker & 19 & 19.2 \\
\hline \multirow[t]{3}{*}{7} & Lower Back Trauma & & \\
\hline & No & 46 & 46.5 \\
\hline & Yes & 53 & 53.5 \\
\hline \multirow[t]{3}{*}{8} & Routine Exercise & & \\
\hline & More than 4 times a week & 10 & 10.1 \\
\hline & Less than 4 times a week & 89 & 89.9 \\
\hline \multirow[t]{4}{*}{9} & Duration of sitting & & \\
\hline & Less than 3 hours & 40 & 40.4 \\
\hline & 3-6 hours & 8 & 8.1 \\
\hline & More than 6 hours & 51 & 51.5 \\
\hline
\end{tabular}

\subsection{Pregnancy}

In our study, we found sacroiliac joint pain more often in female subjects with histories of 2 or 3 pregnancies when compared to those with fewer or none. A review by Pennick and Young in 2013 reported that 2 out of 3 pregnant women experienced pain in the sacroiliac joint region [18]. Ghodke stated that out of 50 study subjects, $26 \%$ were women suffering from postpartum sacroiliac joint pain. This study also revealed that sacroiliac joint pain was more common in multiparous women [19]. However, these results were not reported in the studies by Pennick and Young or Ghodke et al., but some of the factors that cause sacroiliac joint pain include the changes in the patency and strength of the pelvis due to hormonal fluctuation. An increase in the body weight, a lordotic posture, and widening of the pelvic outlet during labor also play roles in these changes to the pelvic anatomy [9, $18-21]$.

\subsection{Body Mass Index}

Obesity is becoming one of the major risk factors for sacroiliac joint dysfunction, which can trigger pain. This is mainly attributed to changes in the supporting cartilage, resulting in pain, stiffness, and restricted activity of the axial muscles [8]. Contrarily, this study showed that more than half of the subjects had normal body mass indexes when compared to previous studies.

\subsection{Trauma}

Holmes et al. conducted retrospective analyses showing that $44-58 \%$ of the patients with sacroiliac joint pain had trauma histories (e.g., falls, traffic accidents, exercise injuries, and fractures); however, the studies did not specify the exact percentages for each predisposing factor [22]. In our study, we found that $54.5 \%$ of the subjects reported fall trauma histories from 1 to 5 years before the first onset of sacroiliac joint pain. These results are consistent with those of the studies by Holmes et al. Fall trauma can eventually lead to damage in the ligaments that weave through the structure of the sacroiliac joint, causing anomalous joint movement and triggering pain from degenerative arthritis $[1,22]$.

\subsection{Activity Rate}

We determined that the activity rate was one of the important predisposing factors for sacroiliac joint pain. The results of our study showed that the majority of our subjects $(89.8 \%)$ did not exercise regularly, while only $10.2 \%$ reported that they participated in routine exercise regimens (4 or more times per week). It has been well established that heavy physical activity and a high exercise rate are among the risk factors of developing sacroiliac joint pain. Contrary to other research studies, we found that the majority of the patients were physically inactive. One possible theory proposed for these results was the reduced flexibility of the sacroiliac joint caused by the atrophy of the muscles and ligaments [23]. However, we believe that it is too soon to propose such a theory because further research is still needed.

\subsection{Sitting Duration}

In this study, $51 \%$ of the subjects reported long sitting durations during the day (more than 8 hours), while $44 \%$ reported that they sat for 1-3 hours. These findings correspond to the occupational histories of the subjects, $50.5 \%$ of which were office workers. Sitting can cause inflammation due to repetitive microtrauma, which causes stretching and damage in the main ligaments of the sacroiliac joint, leading to anomalous joint movements [24, 25].

\subsection{Occupational History}

Our study revealed that office workers were more likely to develop sacroiliac joint pain due to their very long sitting position durations (more than 6 hours). As mentioned above, maintaining a sitting position for a long period of time is associated with repetitive microtrauma to the main ligaments 
that support the sacroiliac joint, leading to pain due to the degenerative arthritis process [26, 27].

\section{CONCLUSION}

The results of this study showed that some of the factors that trigger sacroiliac joint pain are the female gender, being in the 40-59 years old age group, a multiple pregnancy history, sitting for more than 6 hours during the day, and working in an office. However, further research is needed to determine whether there are other sacroiliac joint pain triggers, and to confirm our results.

\section{ETHICS APPROVAL AND CONSENT TO PARTICIPATE}

This study was approved by the ethical committee of Pelita Harapan University (ethical approval number 001/KLKJ/ETIK/VIII/2017).

\section{HUMAN AND ANIMAL RIGHTS}

No Animals were used in this research. All human research procedures followed were in accordance with the ethical standards of the committee responsible for human experimentation (institutional and national), and with the Helsinki Declaration of 1975, as revised in 2013.

\section{CONSENT FOR PUBLICATION}

All participants provided written informed consent to participate.

\section{CONFLICT OF INTEREST}

Both authors of this study, Yusak Mangara Tua Siahaan and Vinson Hartoyo, declare that they have no biomedical financial interests or potential conflicts of interest.

\section{ACKNOWLEDGEMENTS}

Declared none.

\section{REFERENCES}

[1] Cohen SP, Chen Y, Neufeld NJ. Sacroiliac joint pain: a comprehensive review of epidemiology, diagnosis and treatment. Expert Rev Neurother 2013; 13(1): 99-116. [http://dx.doi.org/10.1586/ern.12.148] [PMID: 23253394]

[2] Cohen SP. Sacroiliac joint pain: a comprehensive review of anatomy, diagnosis, and treatment. Anesth Analg 2005; 101(5): 1440-53. [http://dx.doi.org/10.1213/01.ANE.0000180831.60169.EA] [PMID: 16 244008]

[3] Manchikanti L, Singh V, Falco FJE, Benyamin RM, Hirsch JA. Epidemiology of low back pain in adults. Neuromodulation 2014; 17(Suppl. 2): 3-10.

[http://dx.doi.org/10.1111/ner.12018] [PMID: 25395111]

[4] Laslett M. Evidence-based diagnosis and treatment of the painful sacroiliac joint. J Manual Manip Ther 2008; 16(3): 142-52 [http://dx.doi.org/10.1179/jmt.2008.16.3.142] [PMID: 19119 403]

[5] van der Wurff P, Buijs EJ, Groen GJ. Intensity mapping of pain referral areas in sacroiliac joint pain patients. J Manipulative Physiol Ther 2006; 29(3): 190-5. [http://dx.doi.org/10.1016/j.jmpt.2006.01.007] [PMID: 1658 4942]

[6] Visser LH, Nijssen PGN, Tijssen CC, van Middendorp JJ, Schieving J. Sciatica-like symptoms and the sacroiliac joint: clinical features and differential diagnosis. Eur Spine J 2013; 22(7): 1657-64. [http://dx.doi.org/10.1007/s00586-013-2660-5] [PMID: 2345 5949]
[7] Simopoulos TT, Manchikanti L, Singh V, et al. A systematic evaluation of prevalence and diagnostic accuracy of sacroiliac joint interventions. Pain Physician 2012; 15(3): E305-44. [PMID: 22622915]

[8] Irwin RW, Watson T, Minick RP, Ambrosius WT. Age, body mass index, and gender differences in sacroiliac joint pathology. Am J Phys Med Rehabil 2007; 86(1): 37-44.

[http://dx.doi.org/10.1097/PHM.0b013e31802b8554] [PMID: 17304 687]

[9] Sabino J, Grauer JN. Pregnancy and low back pain. Curr Rev Musculoskelet Med 2008; 1(2): 137-41.

[http://dx.doi.org/10.1007/s12178-008-9021-8] [PMID: 1946 8887]

[10] Liliang PC, Liang CL, Lu K, Weng HC, Syu FK. Modified fluoroscopy-guided sacroiliac joint injection: a technical report. Pain Med 2014; 15(9): 1477-80.

[http://dx.doi.org/10.1111/pme.12492] [PMID: 25158990]

[11] Jones A, Regan M, Ledingham J, Pattrick M, Manhire A, Doherty M. Importance of placement of intra-articular steroid injections. BMJ 1993; 307(6915): 1329-30.

[http://dx.doi.org/10.1136/bmj.307.6915.1329] [PMID: 8257 889]

[12] Rosenberg JM, Quint TJ, de Rosayro AM. Computerized tomographic localization of clinically-guided sacroiliac joint injections. Clin J Pain 2000; 16(1): 18-21.

[http://dx.doi.org/10.1097/00002508-200003000-00004] [PMID: 107 41814]

[13] Pekkafahli MZ, Kiralp MZ, Başekim CC, et al. Sacroiliac joint injections performed with sonographic guidance. J Ultrasound Med 2003; 22(6): 553-9.

[http://dx.doi.org/10.7863/jum.2003.22.6.553] [PMID: 1279 5552]

[14] Koski JM, Hammer HB. Ultrasound-guided procedures: techniques and usefulness in controlling inflammation and disease progression. Rheumatology (Oxford) 2012; 51(Suppl. 7): vii31-5.

[http://dx.doi.org/10.1093/rheumatology/kes331] [PMID: 2323 0092]

[15] Vleeming A, Schuenke MD, Masi AT, Carreiro JE, Danneels L, Willard FH. The sacroiliac joint: an overview of its anatomy, function and potential clinical implications. J Anat 2012; 221(6): 537-67. [http://dx.doi.org/10.1111/j.1469-7580.2012.01564.x] [PMID: 229 94881]

[16] Taheri A, Moallemy A, Dehghanian A, Vatankhah P. Evaluation of the relationship between age, gender, and body mass index, and lumbar facet joint pain. Indian J Pain 2016; 30(1): 19-22.

[http://dx.doi.org/10.4103/0970-5333.173454]

[17] DePalma MJ, Ketchum JM, Saullo TR. Multivariable analyses of the relationships between age, gender, and body mass index and the source of chronic low back pain. Pain Med 2012; 13(4): 498-506. [http://dx.doi.org/10.1111/j.1526-4637.2012.01339.x] [PMID: 2239 0231]

[18] Pennick V, Young G. Interventions for preventing and treating pelvic and back pain in pregnancy. Cochrane Database Syst Rev 2017; 18: CD001139.

[19] Ghodke PS, Shete D, Anap D. Prevalence of Sacroiliac Joint Dysfunction in Postpartum Women-A Cross Sectional Study. J Physiother Phys Rehabil 2017; 02(03): 3-5.

[20] Albert HB, Godskesen M, Korsholm L, Westergaard JG. Risk factors in developing pregnancy-related pelvic girdle pain. Acta Obstet Gynecol Scand 2006; 85(5): 539-44. [http://dx.doi.org/10.1080/00016340600578415] [PMID: 1675 2231]

[21] Munro A, George RB, Chorney J, Snelgrove-Clarke E, Rosen NO. Prevalence and predictors of chronic pain in pregnancy and postpartum. J Obstet Gynaecol Can 2017; 39(9): 734-41. [http://dx.doi.org/10.1016/j.jogc.2017.01.026] [PMID: 2862 4445]

[22] Holmes SL, Cohen SP, Cullen MFL, Kenny CD, Wain HJ, David S. Sacroiliac joint pain.Pain Medicine: An Interdiciplinary Case-Based Approach. New York: Oxford University Press 2015; pp. 160-82. [http://dx.doi.org/10.1093/med/9780199931484.003.0010]

[23] Teichtahl AJ, Urquhart DM, Wang Y, et al. Physical inactivity is associated with narrower lumbar intervertebral discs, high fat content of paraspinal muscles and low back pain and disability. Arthritis Res Ther 2015; 17(1): 114.

[http://dx.doi.org/10.1186/s13075-015-0629-y] [PMID: 2594 7906]

[24] Kurosawa D, Murakami E, Ozawa H, et al. A diagnostic scoring system for sacroiliac joint pain originating from the posterior ligament. Pain Med 2017; 18(2): 228-38. [PMID: 28204687]

[25] Kurosawa D, Murakami E, Aizawa T. Groin pain associated with sacroiliac joint dysfunction and lumbar disorders. Clin Neurol Neurosurg 2017; 161: 104-9. 
[http://dx.doi.org/10.1016/j.clineuro.2017.08.018] [PMID: 288 66262]

[26] Lis AM, Black KM, Korn H, Nordin M. Association between sitting and occupational LBP. Eur Spine J 2007; 16(2): 283-98.

[http://dx.doi.org/10.1007/s00586-006-0143-7] [PMID: 1673 6200]
[27] Gupta N, Christiansen CS, Hallman DM, Korshøj M, Carneiro IG, Holtermann A. Is objectively measured sitting time associated with low back pain? A cross-sectional investigation in the NOMAD study. PLoS One 2015; 10(3): e0121159.

[http://dx.doi.org/10.1371/journal.pone.0121159] [PMID: 2580 6808]

\section{(C) 2019 Siahaan and Hartoyo.}

This is an open access article distributed under the terms of the Creative Commons Attribution 4.0 International Public License (CC-BY 4.0), a copy of which is available at: (https://creativecommons.org/licenses/by/4.0/legalcode). This license permits unrestricted use, distribution, and reproduction in any medium, provided the original author and source are credited. 